\title{
Identification of minor products obtained during radiolysis of tributylphosphate (TBP)
}

\author{
Denis Lesage, Henri Virelizier and Christophe K. Jankowski* \\ DCC/DPE/SPEA/SAIS, Centre d'Etudes Nucléaires de Saclay, 91191 Gif-sur-Yvette, France \\ Jean Claude Tabet \\ Laboratoire de Chimie Structurale Organique et Biologique, EP103, Université P. et M. Curie, \\ 4 place Jussieu, 75252 Paris Cedex 05, France
}

Received 11 November 1996

Accepted 20 August 1997

\begin{abstract}
The structure identification of the fraction of minor products obtained during radiolysis of tributylphosphate (TBP), the solvent used in reprocessing of nuclear fuel, is reported. These results were realised from the distillation residue of the EDIT loop. The primary radiolysis formed TBP radical dimerises and is transformed under oxidative nitric acid conditions into several butyl chains substituted hydroxy or nitro phosphates as well as alkylated TBP. The butyl chain hydroxylated phosphate is leading to ketones, ethers and O-ester derivatives. The structures were determined by tandem mass spectrometry (MS-MS) and isotopic labelling techniques as well as by ion filiation and isotopic exchange studies. The analytical method developed consisted of the use of the integrated GC-MS, or GC-MS-MS, isotopic labelling technique. The combination of these techniques enabled to identify and to semi-quantify most of highly functionalised TBP without their prior separation from the post radiolysis mixtures.
\end{abstract}

Keywords: TBP, phosphate, radiolysis, PUREX, tandem mass spectrometry

\section{Introduction}

The degradation of the solvent system during the nuclear fuel reprocessing procedure remains, for both economical and scientific reasons, a major problem to the nuclear energy industry. The extraction of fuel with tributylphosphate (TBP, 1), diluted with an appropriate solvent (e.g., dodecane fraction, hydrogenated tetrahydro propylene or hyfrane, 2) leads to the exposure of this system to radiolysis and inevitably to its degradation. As a result a mixture of over 200 derivative products, most of them in trace quantities is obtained. Some of these products can complex lanthanides and actinides - in particular uranium, plutonium and fission products - and, in this respect, affect a whole reprocessing procedure [1]. The identification of even minor components of solvent degradation mixture is then essential to the process actually used and to design its eventual modifications.

The study of these mixtures was usually performed on laboratory irradiated (simulated) samples as well as on radiolysed solvent system exposed to acidic (nitric acid, $4 \mathrm{~N}$ ) conditions, because of

\footnotetext{
*Author to whom all inquiries should be addressed: C.K. Jankowski, Faculté des Études Supérieures et de la Recherche, Université de Moncton, Moncton N.-B., Canada E1A3E9.
} 

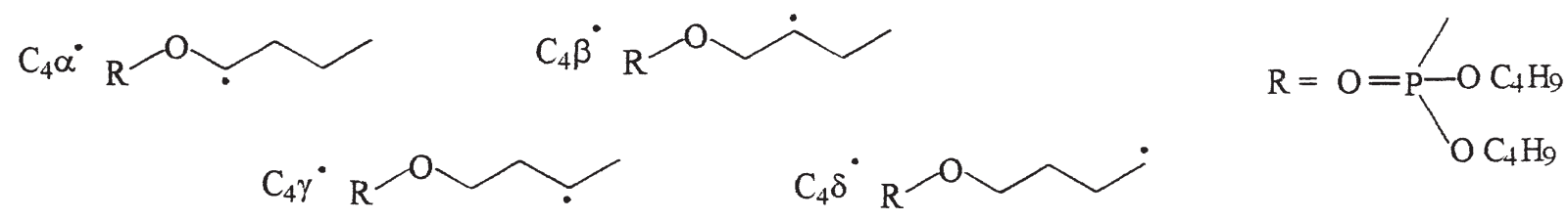

Scheme 1. TBP isomeric radical structures.

the radioactivity, rather than on industrial samples. However, these simulations do often represent situations far from the industrial reality. The EDIT loop in particular was created in order to simulate as closely as possible the solvent degradation during the fuel reprocessing. It is necessary to point out that the heavy metal complexation agents are more concentrated in the residue after the distillation (accounting for up to 9\% of degradation products referred to residual TBP). This preconcentration of specific degradation products increased our interest in the study of this fraction [2]. The analytical difficulties to study these mixtures were among others the low, trace, concentrations of these products, the complexity of these mixtures, the simultaneous presence of various highly functionalised compounds, their interferences and the impossibility of direct quantification of most of these compounds from the unprocessed mixtures, etc.

Since 1982 we have studied these mixtures using different mass spectrometry-gas chromatography (GC-MS) methods [3]. The dimers $\underline{3}$ (TBP-TBP, general formula: O, $\mathrm{O}^{\prime}$-di(dibutylphosphate)yl octanes) (Table 1), which were studied by MS-MS in the previous paper [4], are important molecules because of their ability to complex plutonium [5]. In this paper we report the use of integrated tandem mass spectrometry, GC-MS-MS and stable isotopic labelling methods to study the radiolysed solvent minor degradation products.

The radiolytic degradation of $\underline{1}$ under oxidation conditions leads to the formation of radicals, e.g., $\mathrm{TBP}^{\circ}$, which, after dimerisation to $\underline{3}$ (TBP dimers) or couplings with, e.g., dodecanes, are responsible for the formation of several families of compounds. In the presence of oxygen (air) and nitric acid the oxidation reactions take place leading to the oxidation of butyl chains and formation of, e.g., alcohols, ketones, acids, esters, ethers, nitrates and nitro derivatives. All these products are issued from the isomeric radical $1\left(\mathrm{TBP}^{\circ}\right)$. The butyl chain of TBP can form four different radicals - three of them being secondary (in positions 1, 2 and 3) and one primary (in position 4) (Scheme 1). All these radicals, as well as radicals containing oxygen function, can react with many components of mixture. However, some unsaturated compounds, also issued from the TBP radicals or from hydroxylated TBP chain dehydration, are formed. The radiolysis, which is very unspecific and unselective, enhances the reaction of $\mathrm{TBP}^{\circ}$ with a variety of compounds. The presence of alkoxy TBP as well as $\mathrm{O}-$ and C-esters were observed.

The main degradation products are already known (Scheme 2) [6,7]. Nevertheless, comparing our results, discussed in this paper, with the previous ones, we have developed new methodology enabling the identification of isomers of highly functionalised monomeric and dimeric TBP derivatives as well as to advance the hypothesis of specific formation of some of these isomeric compounds. The identification of new or unreported families of compounds was also related (e.g., families of TBP dimers, ethers, $\mathrm{O}$ - and C-esters, ...). The instrumental techniques used in our study enabled to achieve a higher sensibility level and reach much lower detection limits.

Some of experiments described in this paper enabled to confirm the hypothetical relationship existing among the families of compounds presented in Scheme 2 and modified some reaction pathways. For instance, phosphate-phosphonates are not formed from the HDBP. The TBP dimer studies [4] confirmed this new hypothesis. However, the absence of some families presented in Scheme 2 and not reported 
Table 1

Main degradation products observed

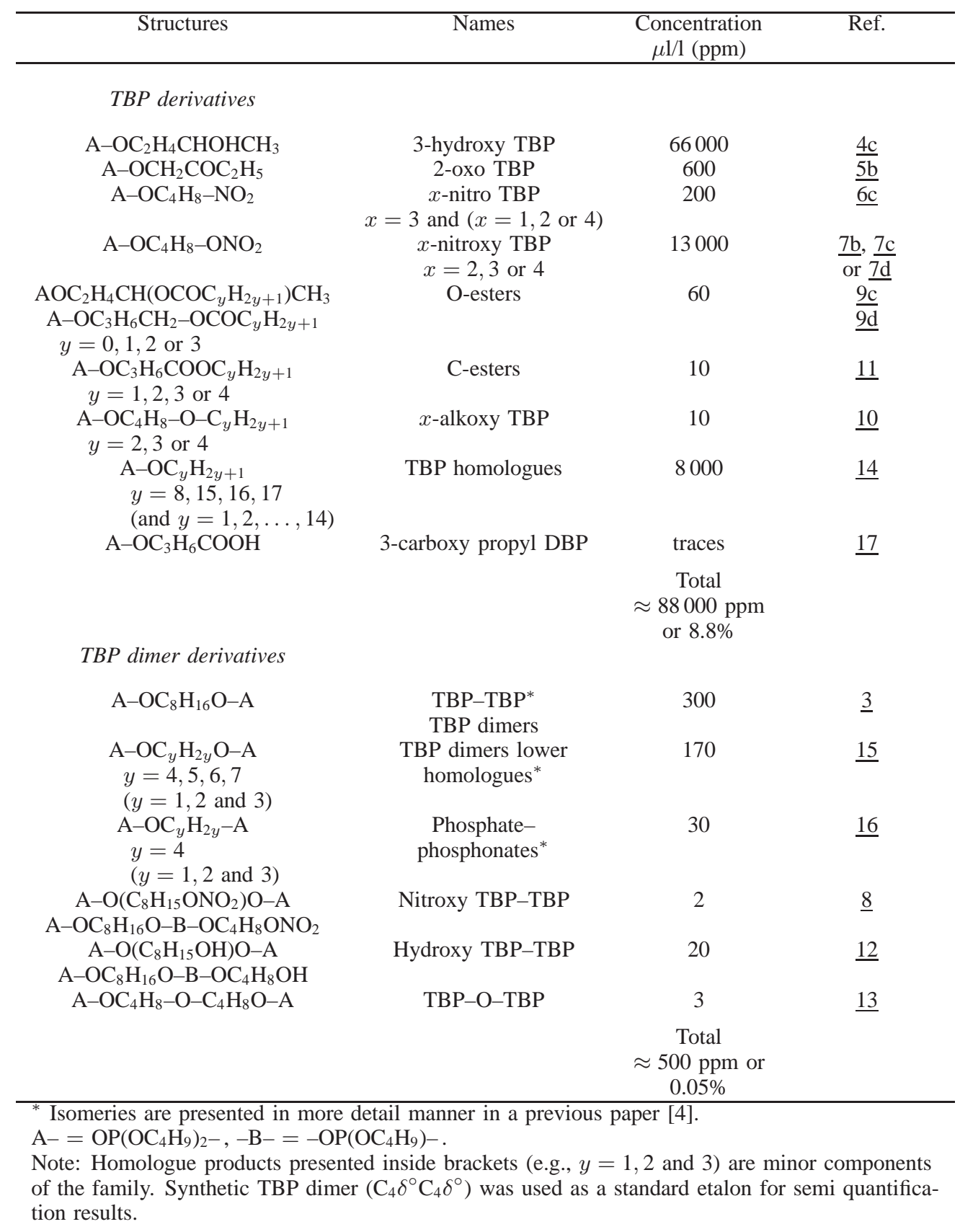

in our study can be explained by different origins of the samples. In the EDIT loop, which simulated the nuclear fuel reprocessing, the absence of acid alkylphosphate is related to the elimination of HDBP by basic treatment before its reaction. Relatively weaker concentration of dodecane derivatives in this fraction resulted from the fact that these volatile products were eliminated from the distillation residue. 


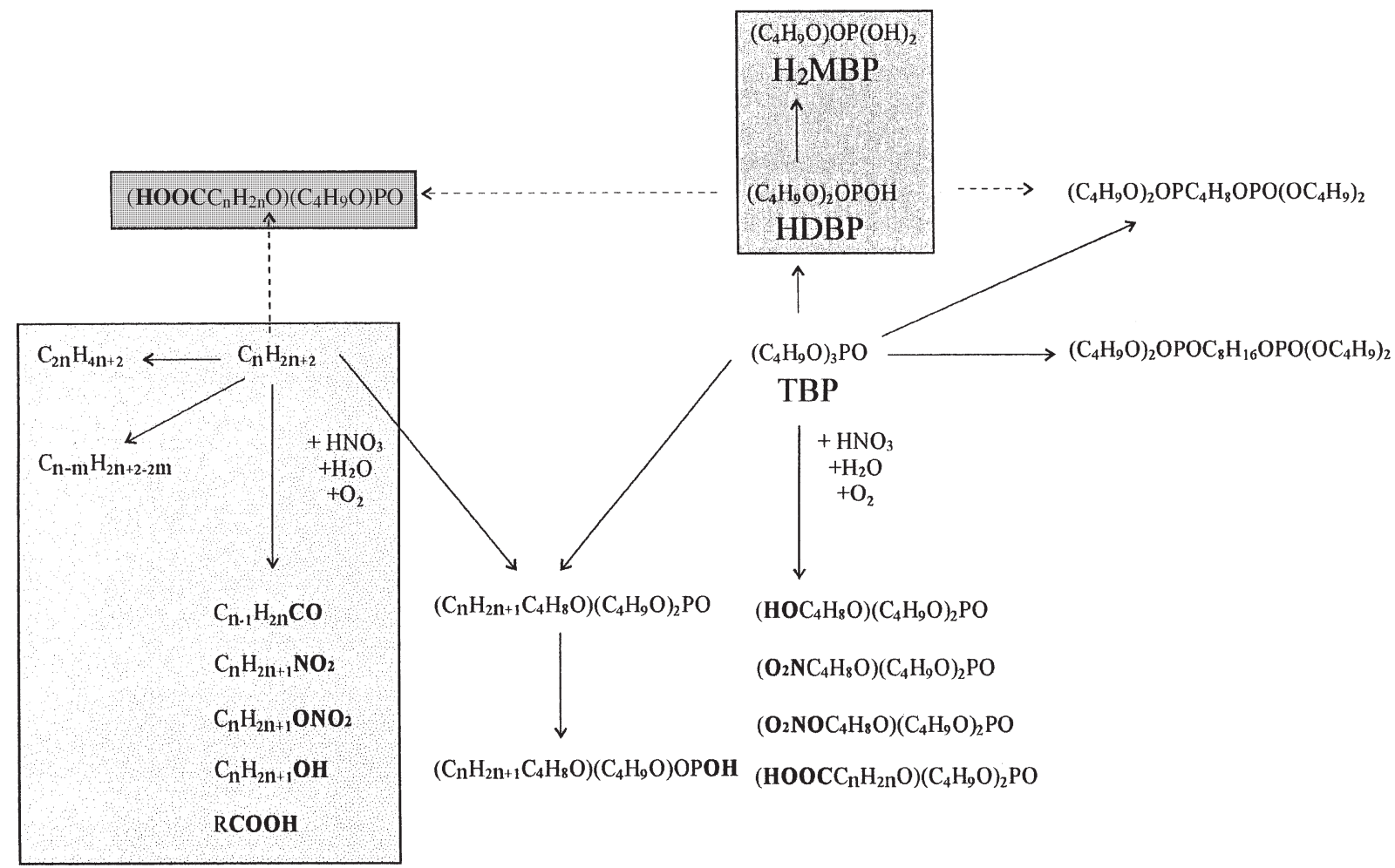

\footnotetext{
This fraction was eliminated in this work by distillation

T. This fraction was eliminated in this work by alcaline treatment

$\square$ These products were not formed in this work

$-\rightarrow$ Reaction not observed in this work
}

Scheme 2. Formation of radiolysis products accumulated in the organic phase of the extraction system TBP- $n$-paraffin-aqueous solution of $\mathrm{HNO}_{3}$ (quoted after Adamov [6,7]). The same family homologues are correlated by diagonal lines.

The identification of new degradation products, most of them being present in trace quantities, using spectrometric techniques was confirmed in our laboratory by some specially designed synthesis. In a series of hydroxy derivatives a major 3-hydroxy TBP $(\underline{4 \mathrm{c}})$ as well as 2 -oxo TBP $(\underline{5 b})$ in a keto series were synthesised together with numerous TBP dimers $\underline{3}$, some of them with appropriate deuteration [4].

The 3-hydroxy TBP $(\underline{4 c})$ is a major hydroxy compound formed during radiolysis. Its particular stability and resistance toward further oxidation is discussed in a more detailed manner in the next sections. The hydroxy TBP (4) derivatives are playing a key role among minor degradation products. They are intermediates for formation of ketones, aldehydes (unobserved) and acids, nitrates, O-esters as well as ethers and unsaturated derivatives of TBP radical. Some of them are readily transformed in higher oxidation products, however, the 3-hydroxy TBP ( $\underline{4 c)}$ is stable and resists nitric acid oxygen oxidation conditions.

The nitro TBP derivatives can also undergo some transformations to produce in particular some nitroso derivatives and by Nef reaction [8] ketones, aldehydes, carboxylic acids and C-ester derivatives of TBP. In an analogous manner the Victor-Meyer reaction on nitroso TBP leads to carboxylic acids. 
The oxidised TBP dimer products were also observed (hydroxylation, nitration, ketonisation). It is not clear, however, if this oxidation takes place by the formation of dimers followed by oxidation or by coupling of radicals $\mathrm{TBP}^{\circ}$ to oxidised forms of $\mathrm{TBP}^{\circ}$. Some of these oxidised dimers identified in this mixture are presented in this study (e.g., hydroxy TBP-TBP) and also used for calibration purpose for gas chromatography and for tandem MS experiments. Finally, these reference or model compounds enabled to study fragmentation mechanisms as well.

The stable isotopes $\mathrm{D},{ }^{18} \mathrm{O}$ and ${ }^{15} \mathrm{~N}$ labelling techniques enable to follow the formation of labelled molecules, during radiolysis of hexadeuterated TBP molecules, $\mathrm{H}_{2}{ }^{18} \mathrm{O}, \mathrm{HN}^{18} \mathrm{O}_{3}$ or $\mathrm{H}^{15} \mathrm{NO}_{3}$, and to propose a mechanistic interpretation of these phenomena. The use of this specific labelling is replacing, in a sort, a complex synthesis of many difficult to synthesise molecules. It is obvious that in this series of organo-phosphates most reference compounds are not commercially available and were not synthesised or discussed in the literature.

The analytical technique developed to study a nuclear fuel solvent degradation should be very reliable, sensitive and flexible. In fact, the study of mixtures using tandem mass spectrometry (MS-MS) fully answers this requirement. The flexibility requirement should also be realised because industrial original and simulated samples are coming from different experimental conditions, representing a real life situation. Because of an important variation of radiation dose, dose rate, acid-solvent ratios, alkaline treatment, derivatisation of radiolytes, etc., the analytical technique should be virtually independent of these experimental conditions. The databank collected in this paper on degradation products obtained in such studies enables an unambiguous identification of numerous isomeric products and their semi quantification (means referred to an internal standard of known concentration, for example).

The parallel study of specific ions obtained via labelled and unlabelled processes using MS-MS (or in the GC-MS-MS mode) is the most rapid, original and reliable approach to this problem, even though both product families can undergo isotopic exchange.

The laboratory simulation of industrial conditions, using the EDIT loop procedure to study the degradation of a real solvent system, consisted of integration of many physical and chemical treatments (e.g., alkali and acid treatments, distillation) to simulate the industrial solvent retreatment. Indeed, these chemical and physical treatments must be taken into account because they can modify the degradation product ratios as a result of possible secondary reactions. The results presented in this paper originate from treated sample. The fractions of simulated nuclear fuel reprocessing solvent (originate from EDIT) were fractionalised using steric exclusion chromatography [5]. In this way only heavy degradation products are studied in this paper. The lighter fraction containing a dilution solvent (dodecane) and their derivatives was not presented. As a consequency to this limitation and as expected the cold fraction (non radioactive) was studied. However, the methodology developed in this study is perfectly transferable to the hot (radiactive) sample and other fraction treatments.

\section{Experimental}

\subsection{Mass spectrometry}

All mass spectra and low energy CID spectra were obtained using a triple quadrupole tandem mass spectrometer (R-30-10 Nermag). The samples were introduced via a gas chromatograph (Delsi) 
equipped with CPSil 19 length $50 \mathrm{~m}, 32 \mu \mathrm{m}$ internal diameter capillary column or by direct introduction mode. MS and MS/MS spectra were calculated as averages of ten and recorded on a PDP11 computer.

The following source operating conditions were used: electron energy $85 \mathrm{eV}$, source temperature $100^{\circ} \mathrm{C}$, ammonia pressure $10^{-1}$ Torr in the source housing, emission current $180 \mu \mathrm{A}$. In order to perform an $\mathrm{Ar}$ induced collision processes, a pressure of $P_{\mathrm{Ar}}=3 \times 10^{-2}$ Torr and a collision energy of $30 \mathrm{eV}$ were applied.

\subsection{Sample and labelled molecules}

The samples studied are the residue of distillation from the EDIT loop. This loop was created in order to simulate as close as possible the Organic Effluent Treatment (OET) realised during the nuclear fuel reprocessing [2,9-11]. During this reprocessing the solvent underwent different chemical (acid or base treatments) as well as physical (distillation) treatments.

Labelled TBP molecules were prepared by reacting $\mathrm{POCl}_{3}$ with labelled alcohols in a pyridine solution [1]. 1,1-d2 butanol was purchased from CEA Eurisotope (France). Two other bideuterated butanols (2,2-d2 butanol and 3,3-d2 butanol) were synthesised via $\mathrm{LiAlH}_{4}$ reduction of corresponding butyrates [10] bought from Aldrich Chemicals. In order to limit the ether used during the extraction, which is an obstacle for the reaction with $\mathrm{POCl}_{3}$, the ratios of reagents are as used by Raederstorff [11]. The labelled compounds, $\mathrm{H}_{2}{ }^{18} \mathrm{O}(95 \%), \mathrm{HN}^{18} \mathrm{O}_{3}(50 \%), \mathrm{H}^{15} \mathrm{NO}_{3}(98 \%)$, were purchased from Aldrich Chemicals.

\subsection{Irradiation}

Irradiation of labelled extracting systems was carried out at room temperature using $\gamma$-rays from ${ }^{60} \mathrm{Co}$ bomb:

- respectively, $1,1,1^{\prime}, 1^{\prime}, 1^{\prime \prime}, 1^{\prime \prime}$-d6 TBP, or $2,2,2^{\prime}, 2^{\prime}, 2^{\prime \prime}, 2^{\prime \prime}$-d6 TBP or $3,3,3^{\prime}, 3^{\prime}, 3^{\prime \prime}, 3^{\prime \prime}$-d6 TBP $30 \%$, dodecane $/ \mathrm{HNO}_{3} 4 \mathrm{~N}, \mathrm{H}_{2} \mathrm{O}$

- TBP $30 \%$, dodecane/ $/ \mathrm{HN}^{18} \mathrm{O}_{3} 4 \mathrm{~N}, \mathrm{H}_{2} \mathrm{O}$, or TBP $30 \%$, dodecane/ $/ \mathrm{HNO}_{3} 4 \mathrm{~N}, \mathrm{H}_{2}{ }^{18} \mathrm{O}$;

- TBP $30 \%$, dodecane $/ \mathrm{H}^{15} \mathrm{NO}_{3} 4 \mathrm{~N}, \mathrm{H}_{2} \mathrm{O}$;

- TBP 30\%, dodecane/ $\mathrm{DNO}_{3} 4 \mathrm{~N}, \mathrm{D}_{2} \mathrm{O}$.

The dose rate was $10 \mathrm{kGy} / \mathrm{h}$ for 60 hours. One $\mathrm{ml}$ TBP or labelled TBP samples were irradiated in $5 \mathrm{ml}$ sealed tubes.

\section{Results and discussion}

The identification of the compounds obtained during degradation reprocessing solvent is presented in the following sections. The nitrogen containing derivatives of TBP and its dimers are presented in Section 3.1 followed by oxygenated derivatives (hydroxy, keto, etc.) in Section 3.2. Then in Section 3.3 we discuss the problem related to isotopic labelling $\left(\mathrm{D},{ }^{18} \mathrm{O}\right)$ of these compounds, and finally, in Section 3.4 we present all other identified compounds for both families.

The radiolysis of the system in the presence of ${ }^{18} \mathrm{O}$ labelled water or nitric acid enables the identification of all oxygenated molecules by the comparison of this series to the deries with two atomic mass units shift when one ${ }^{18} \mathrm{O}$ isotope is introduced. The MS-MS technique must be used to study these mixtures because of the simultaneous presence of labelled and unlabelled compound in a mixture. 


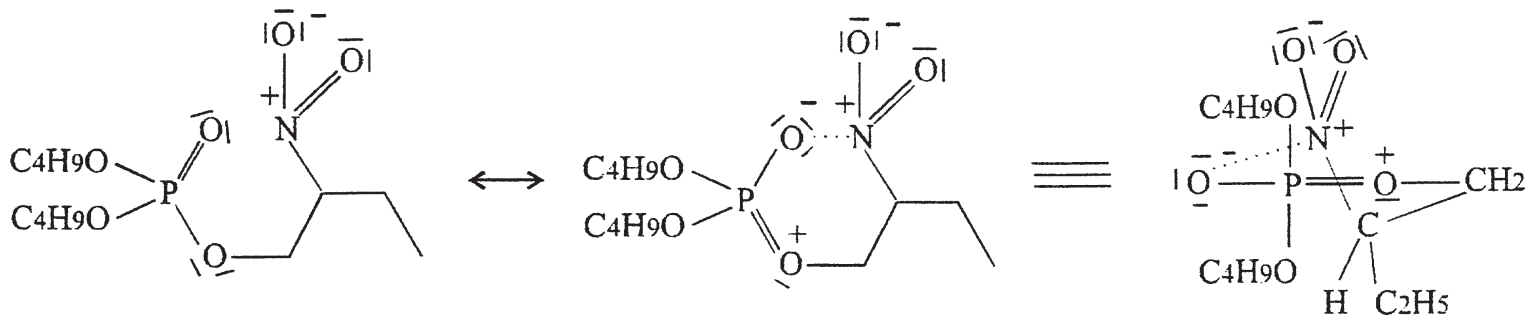

Scheme 3. 3-nitro TBP conformation.

1-Nitro TBP

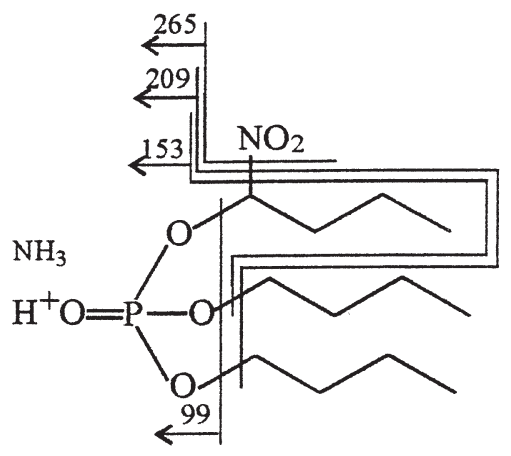

$\mathrm{MNH}_{4}{ }^{+} \mathrm{m} / \mathrm{z} 329$
2-Nitro TBP

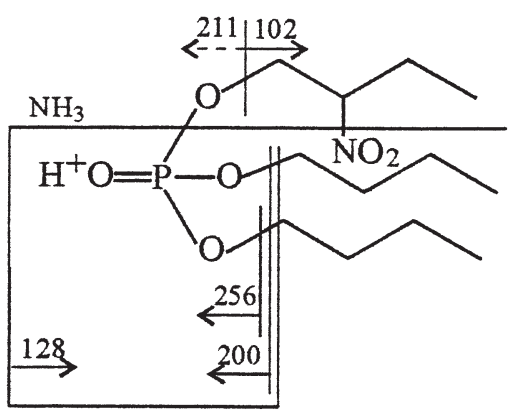

$\mathrm{MNH}_{4}{ }^{+} \mathrm{m} / \mathrm{z} 329$
3-Nitro TBP

(or 4-nitro TBP)

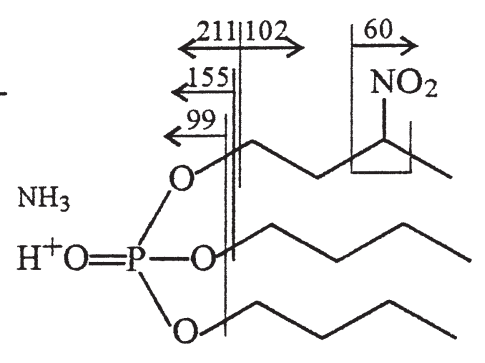

$\mathrm{MNH}_{4}{ }^{+} \mathrm{m} / \mathrm{z} 329$

Scheme 4. Low energy CID fragmentations of the four $x$-nitro TBP.

\subsection{Nitrogen containing derivatives}

\subsubsection{Nitro TBP derivatives}

The nitrogen containing derivatives series observed in TBP radiolysis, the nitro TBP derivatives, were first studied using ammonia chemical ionisation desorption technique (DCI/NH3). Both pseudomolecular ions at $\mathrm{MNH}_{4}^{+}\left(m / z\right.$ 329) as well as $\mathrm{MH}^{+}(m / z 312)$ were observed. The use of $\mathrm{ND}_{3}$ as a chemical ionisation gas does not show any exchange reaction, however, the ${ }^{18} \mathrm{O}$ labelled water-nitric acid system leads to a partial exchange and to double ${ }^{18} \mathrm{O}$ labelling of nitro derivatives.

In the sample exposed to strong radiation, coming from simulated solvents without treatment, equal quantities of all four mono nitro isomers of TBP were observed. The reaction performed under softer condition, in an industrial or in an experimental reactor (e.g., EDIT), leads to one isomer only, 3nitro TBP $\underline{6 c}$. The particular stability of $\underline{6 c}$ isomer should be related to a formation of six member cycle between the 3-nitro group and a phosphate (Scheme 3) combine to a particular stability of the TBP radical in this position. The other isomers (1,2 and 4-nitro TBP) were probably transformed in secondary degradation products during solvent treatment. The CID spectra for four isomers are reported in Scheme 4 and confirmed by ${ }^{18} \mathrm{O}$ and ${ }^{15} \mathrm{~N}$ experiments.

\subsubsection{Nitrates of $T B P$}

This series of nitrogen containing oxidised TBP derivatives is more abundant than the previous one. The TBP nitrate structures were established using the following experiments. Because of the fact that the splitless injection of these compounds leads to their complete decomposition, the on-column mode 
of injection, which enables to record their spectra, was used. The DCI technique was chosen to follow the evolution of the TBP nitrates. The ${ }^{18} \mathrm{O}$ labelling experiments leads to a one-fold labelling only of this fraction. This result is discussed in a more detailed manner in Section 3.3.

Three nitrates present, the compounds having $-\mathrm{ONO}_{2}$ radical attached to $\mathrm{C} 2 \underline{7 \mathrm{~b}}, \mathrm{C} 3 \underline{7 \mathrm{c}}$ and $\mathrm{C} 4 \underline{7 \mathrm{~d}}$ carbons, respectively, were identified. These three compounds cannot be separated by DCI. However, the nitrate at $\mathrm{C} 1 \underline{7 \mathrm{a}}$ carbon of the butyl chain being next to a phosphate group is not detected. The hexadeuterated TBP butyl carbon at $1,1,1^{\prime}, 1^{\prime}, 1^{\prime \prime}, 1^{\prime \prime}$ does not show any nitrate formation in this position. One possible explanation of this observation is the decomposition of the nitrate at $\mathrm{C} 1$ because of the activation of this carbon by two electron attracting substituents $\left(\mathrm{ONO}_{2}\right.$ and $\left.\mathrm{OPO}_{3} \mathrm{R}_{2}\right)$ conferring the acetal or gemdiol diester character to this isomer.

\subsubsection{Nitrogen containing derivatives of TBP dimers}

The CID experiments on the DCI obtained molecular ion $\mathrm{MH}^{+}$for nitroxy derivatives of TBP dimer $\underline{8}$ confirmed presence of two compounds. The mono nitroxy TBP dimer $\left(\mathrm{O}, \mathrm{O}^{\prime}\right.$-di(dibutylphosphate)yl 1,8-nitrooctane) bearing an 1,8-octane chain between two phosphates and nitroxy group attached on this chain together with the second mono nitroxy TBP dimer with an 1,8-octane chain and a nitro group attached to one of the remaining butyl chain were identified (Fig. 1). Although a position of $\mathrm{ONO}_{2}$ group on the chains was not rigorously established, we can reasonably presume that the $\mathrm{ONO}_{2}$ radical is substituted on $\mathrm{C} 2, \mathrm{C} 3$ and/or $\mathrm{C} 4$. Obtaining both nitroxy isomers of TBP dimers means that the nitration could be afforded before or after a dimerisation of the TBP. However, the small quantity of these compounds made it unable to establish this route by detection of dinitroxy dimers. In this series the presence of the normal octane chain linked compounds is confirmed and related to a most favourable (and favoured) and a less hindered structure.

\subsection{Oxygenated TBP and TBP-TBP derivatives}

In this section several oxygen bearing TBP or its dimer derivatives are described. The step by step oxidation of a butyl chain of TBP leads gradually from alcohol (four isomers - one primary and three secondary alcohols), to ketones or aldehydes, than to acids. The hydroxy TBP is involved in the series of reactions with formation of, e.g., ethers and esters. The dibutylphosphate C-esters are also formed as a result of esterification of carboxylic acid function bearing TBP. Finally, the hydroxylated TBP dimers and covalent TBP dimers linked by an ether function are identified.

\subsubsection{Hydroxy TBP derivatives.}

Hydroxy, keto and carboxylic acid phosphate derivatives. The most prominent representative of this family of oxygenated TBP is 3-hydroxybutyl dibutyl phosphate (3-hydroxy TBP) $\underline{4 c}$. The absence of three other alcohols in this series should be reported. The 1-hydroxy TBP has an hydroxyl in a hemiacetal or gemdiol monoester position which leads either to the obtaining of acidic dibutylphosphate (HDBP) (Scheme 5) or to the phosphate assisted dehydration reaction. On the other hand, the oxidation of 2-hydroxy TBP or 4-hydroxy TBP should be facilitated by the $\alpha$-to hydroxyl hydrogen mobility as shown in Scheme 6.

Among three possible ketones, the 2-oxo TBP $\underline{5 b}$ only was identified. The radiolysis of deuterated TBP and ${ }^{18} \mathrm{O}$ exchange with ${ }^{18} \mathrm{O}$ labelled water confirmed the presence of only one isomer and its position on a $\mathrm{C} 2$ of the butyl chain. Its particular stability should be related to an easy enolisation of this system confirmed in a $\mathrm{D}_{2} \mathrm{O} / \mathrm{DNO}_{3}$ experiments which allow such an exchange. These activation 


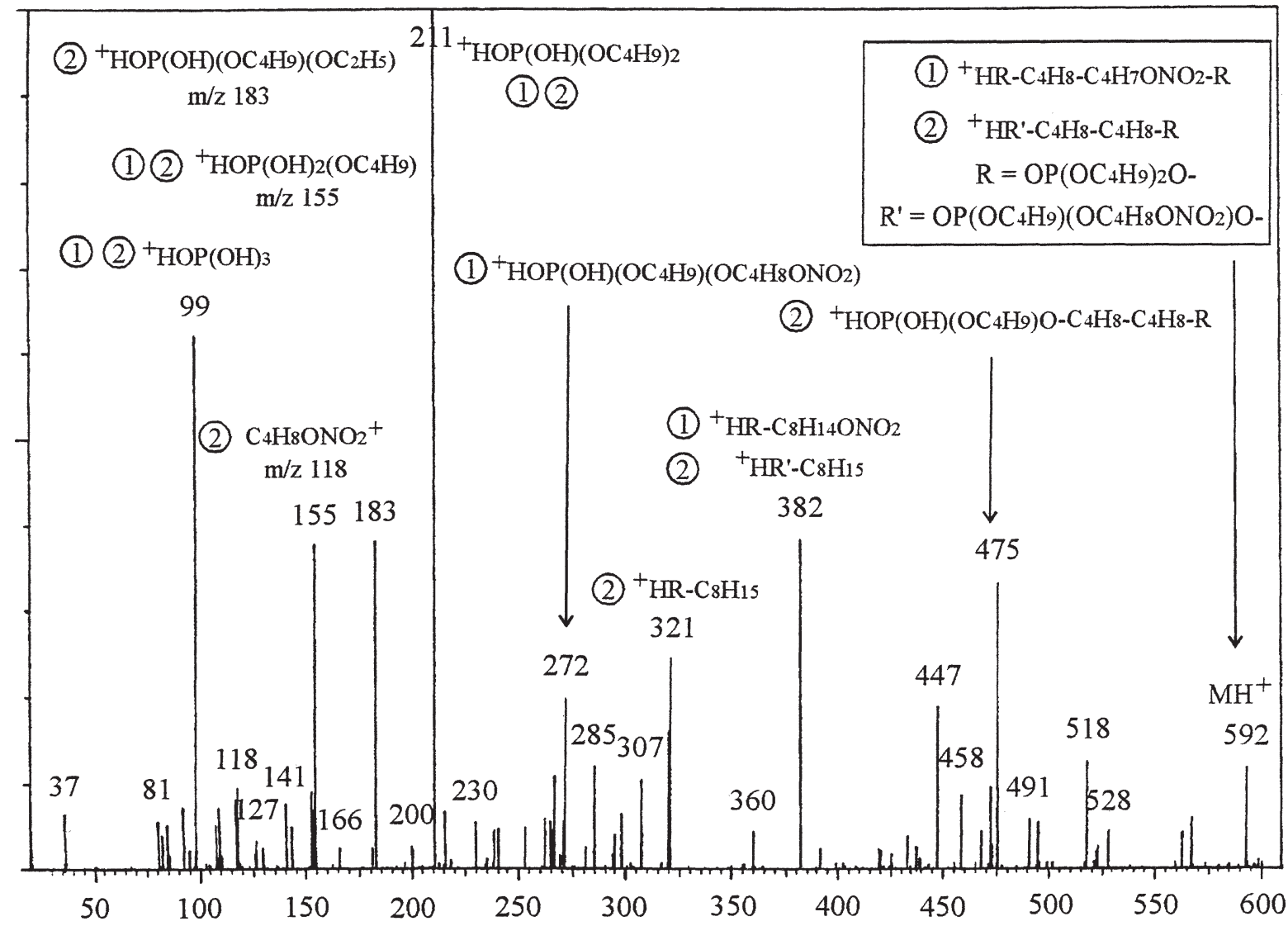

Figure 1. CID spectra $\left(E_{\mathrm{lab}}=30 \mathrm{eV}, P_{\mathrm{Ar}}=4 \times 10^{2}\right.$ Torr $)$ of protonated nitroxy TBP-TBP $\left(\mathrm{MH}^{+}, \mathrm{m} / z\right.$ 592) prepared under $\mathrm{Cl} / \mathrm{NH}_{3}$ conditions.

reactions are leading to a further oxidation, 2-ketone or carboxylic acid on carbon 4, for example, are obtained.

The particular stability and resistance toward oxidation of the 3-hydroxy TBP enabled this alcohol to form the O-esters $\underline{9 \mathrm{c}}$ and some alkoxy-TBP $\underline{10}$. It is necessary to point out that the 1,3-diols mono esterified (e.g., 3-hydroxy 1-acetoxy propane system) are known as being resistant to the oxidation. Our attempt to oxidise this system were unsuccessful.

However, the 3-hydroxy TBP, does not display the intramolecular H-bonding (toward the phosphate). The intermolecular bonding was detected instead using both RMN and IR techniques. These results were confirmed by a specific deuteration experiment by the partial loss of two deuteriums from the $\mathrm{C} 2$ of the butyl chain. This isomer only was observed after radiolysis. The fast oxidation of primary hydroxyl to aldehyde (undetected under those strongly oxidative conditions) than to an acid is not unusual. The detection of this carboxylic acid by $\mathrm{DCI} / \mathrm{NH}_{3}\left(\mathrm{MH}^{+} m / z 297, \mathrm{MNH}_{4}^{+} \mathrm{m} / z\right.$ 314), confirmed by double ${ }^{18} \mathrm{O}$ exchange experiments $\left(\mathrm{MH}^{+} \mathrm{m} / z 301, \mathrm{MNH}_{4}^{+} \mathrm{m} / z 318\right)$, fits well this hypothesis. Assuming an equal acidity of both methylenes $\mathrm{C} 1$ and $\mathrm{C} 3$ hydrogens, from two possible enol formation this having $\alpha, \beta$ double bond is assisted by the phosphate. However, no apparent difference in a stability of these two enols can be deduced from the specifically deuterated (on C3 carbon of the butyl chain) experiments. 


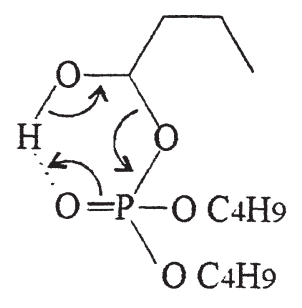

1-hydroxy TBP<smiles>CCCC(=O)OP(=O)(O)OCC</smiles>

Dibutylphosphate acid (HDBP)<smiles>CCOP(=O)(OCC)OC1(O)CCCCC1CC</smiles>

1-hydroxy TBP<smiles>CC/C=C/OP(=O)(OCC)OCCO</smiles>

1-butenyl dibutylphosphate

Scheme 5. 1-hydroxy TBP decomposition.<smiles>CCOP(=O)(OCC)OCC(O)CC</smiles>

2-hydroxy TBP<smiles>CCOP(=O)(OCC)OCCCCO</smiles>

4-hydroxy TBP

Scheme 6. 2-hydroxy TBP and 4-hydroxy TBP oxidation.

O-ester, C-ester and ether phosphate derivatives. About thirty oxygenated compounds, corresponding to $\mathrm{MH}^{+}$homologous ion series $m / z 311,325,339,353$, formed by $\mathrm{NH}_{3}$ chemical ionisation, are observed (Fig. 2). For each series 4-7 (e.g., $m / z$ 339) isomers were identified by GC-MS technique. The unsuccessful search for a mobile hydrogen, by $\mathrm{ND}_{3}$ chemical ionisation, indicates that these compounds are not hydroxy phosphates. The oxygen exchange with $\mathrm{H}_{2}{ }^{18} \mathrm{O}$ during irradiation shows the presence of at least three families of oxygenated compounds: ethers, O-esters and C-esters (corresponding to incorporation of $0,2(40 \%)$ and $2(27 \%){ }^{18} \mathrm{O}$ atoms, respectively, observed). The comparison of CID spectra of labelled and unlabelled compounds allow then to identify all oxygenated homologues (Scheme 7).

The radiolysis of carbon 3 hexadeuterated TBP $\left(3,3,3^{\prime}, 3^{\prime}, 3^{\prime \prime}, 3^{\prime \prime}\right.$-d6 TBP) leads to labelled oxygenated derivatives. The presence of odd deuterium atoms in some molecules, formed by radiolysis and detected by GC-MS CI/NH 3 technique, enabled to confirm the oxygen position on butyl chain for both $\mathrm{O}$-esters $\underline{9 \mathrm{c}}, \underline{9 \mathrm{~d}}$ and ethers $\underline{10}$. These stable isotopic labelling results show that this technique is an useful tool for the formation mechanism studies. The number of deuterium retained by the molecules mainly depends then on the way they are formed. These results are discussed in Section 3.3. 


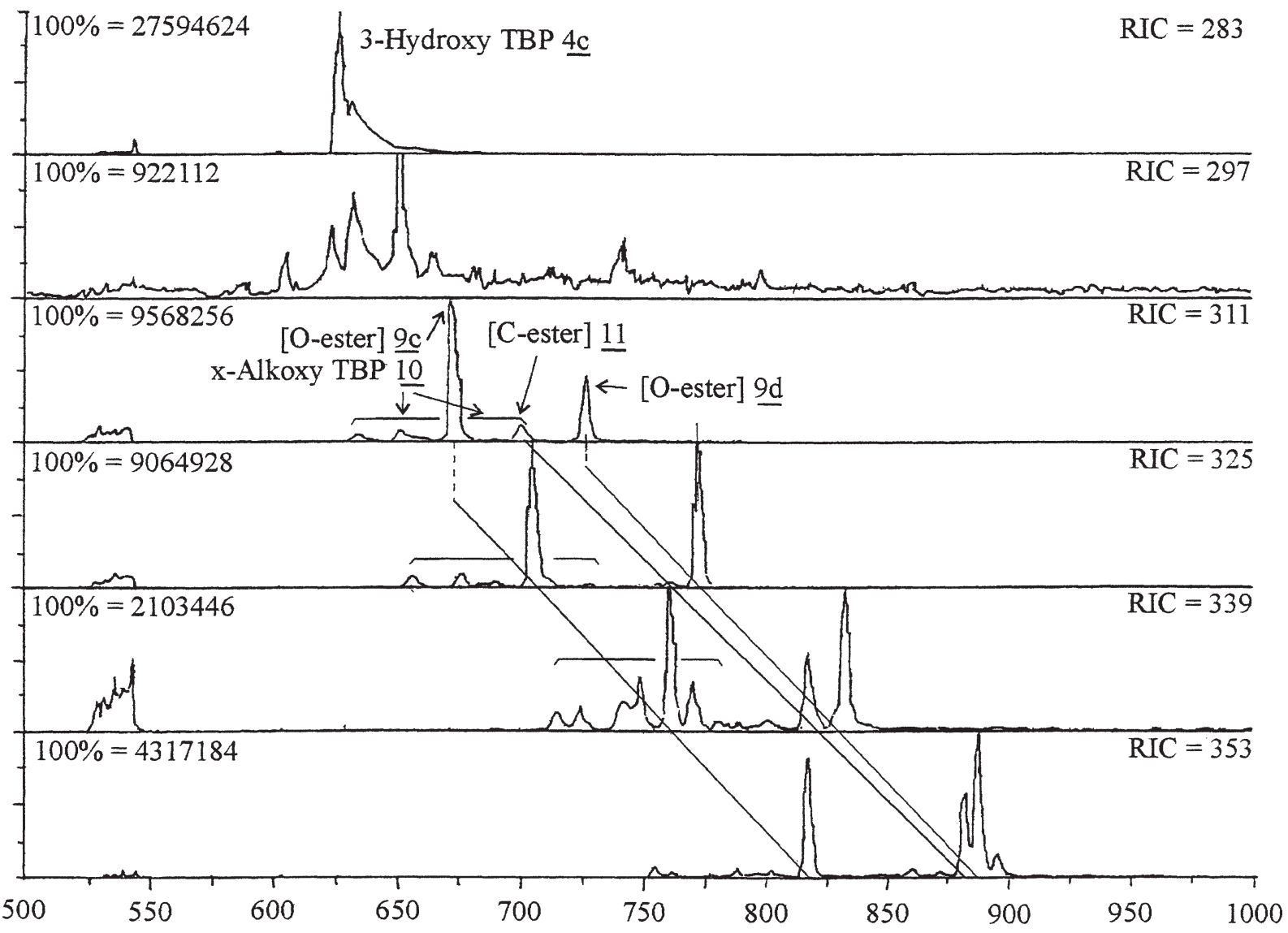

Figure 2. Oxygenated compounds $\left(\mathrm{MH}^{+}\right)$obtained under $\mathrm{Cl} / \mathrm{NH}_{3}$ conditions.

\subsubsection{Hydroxy TBP dimer derivatives}

The pseudomolecular protonated ion at $\mathrm{MH}^{+} m / z 547$, obtained by $\mathrm{NH}_{3}$ chemical ionisation, reveals also the formation of oxygenated TBP dimers. The presence of a mobile hydrogen shows in this case the presence of hydroxylated compounds. The low energy CID spectra of these protonated molecules enabled to identify two hydroxy TBP dimers families 12: first one having an hydroxy function on the octane chain (diagnostic ion at $m / z 127, \mathrm{C}_{8} \mathrm{H}_{14} \mathrm{OH}^{+}$) and the second one on the butyl chain (diagnostic ion at $m / z 475 \mathrm{H}^{+} \mathrm{OP}\left(\mathrm{OC}_{4} \mathrm{H}_{9}\right)_{2}-\mathrm{OC}_{8} \mathrm{H}_{16} \mathrm{O}-\mathrm{PO}\left(\mathrm{OC}_{4} \mathrm{H}_{9}\right) \mathrm{OH}$ and $m / z 321$ $\left.\mathrm{H}^{+} \mathrm{OP}\left(\mathrm{OC}_{4} \mathrm{H}_{9}\right)_{2} \mathrm{OC}_{8} \mathrm{H}_{15}\right)$. For these two isomeric hydroxy TBP dimers it was, however, impossible to identify the exact position of the $\mathrm{OH}$ radical on either octane or butyl chains.

Mobile hydrogen is observed, with $\mathrm{ND}_{3}$ chemical ionisation, when these last compounds are directly introduced in the mass spectrometer source $\left(\mathrm{DCI} / \mathrm{ND}_{3}\right)$. However, when these compounds are separated by GC before introduction on the mass spectrometer the absence of mobile hydrogen is observed. This result is explained by thermic degradation of hydroxy TBP dimers $\underline{12}$ on the chromatographic column. Thus, in these conditions a new series of weaker oxygenated TBP dimers, corresponding to $\mathrm{H}^{+} \mathrm{OP}\left(\mathrm{OC}_{4} \mathrm{H}_{9}\right)_{2}-\mathrm{OC}_{4} \mathrm{H}_{8}-\mathrm{O}-\mathrm{C}_{4} \mathrm{H}_{8} \mathrm{O}-\mathrm{PO}\left(\mathrm{OC}_{4} \mathrm{H}_{9}\right)_{2}$ formula (TBP-O-TBP $\underline{13}$ ), is observed.

The diagnostic ion at $m / z 283$, corresponding to a $\mathrm{H}^{+} \mathrm{OP}\left(\mathrm{OC}_{4} \mathrm{H}_{9}\right)_{2}-\mathrm{OC}_{4} \mathrm{H}_{8} \mathrm{OH}$, in the CID spectra of the protonated ether derivatives, shows the oxygen linked two TBP molecule structures. For this family of derivatives eight isomers were observed by $\mathrm{GC}-\mathrm{MS} \mathrm{NH}_{3}$ chemical ionisation. It was 


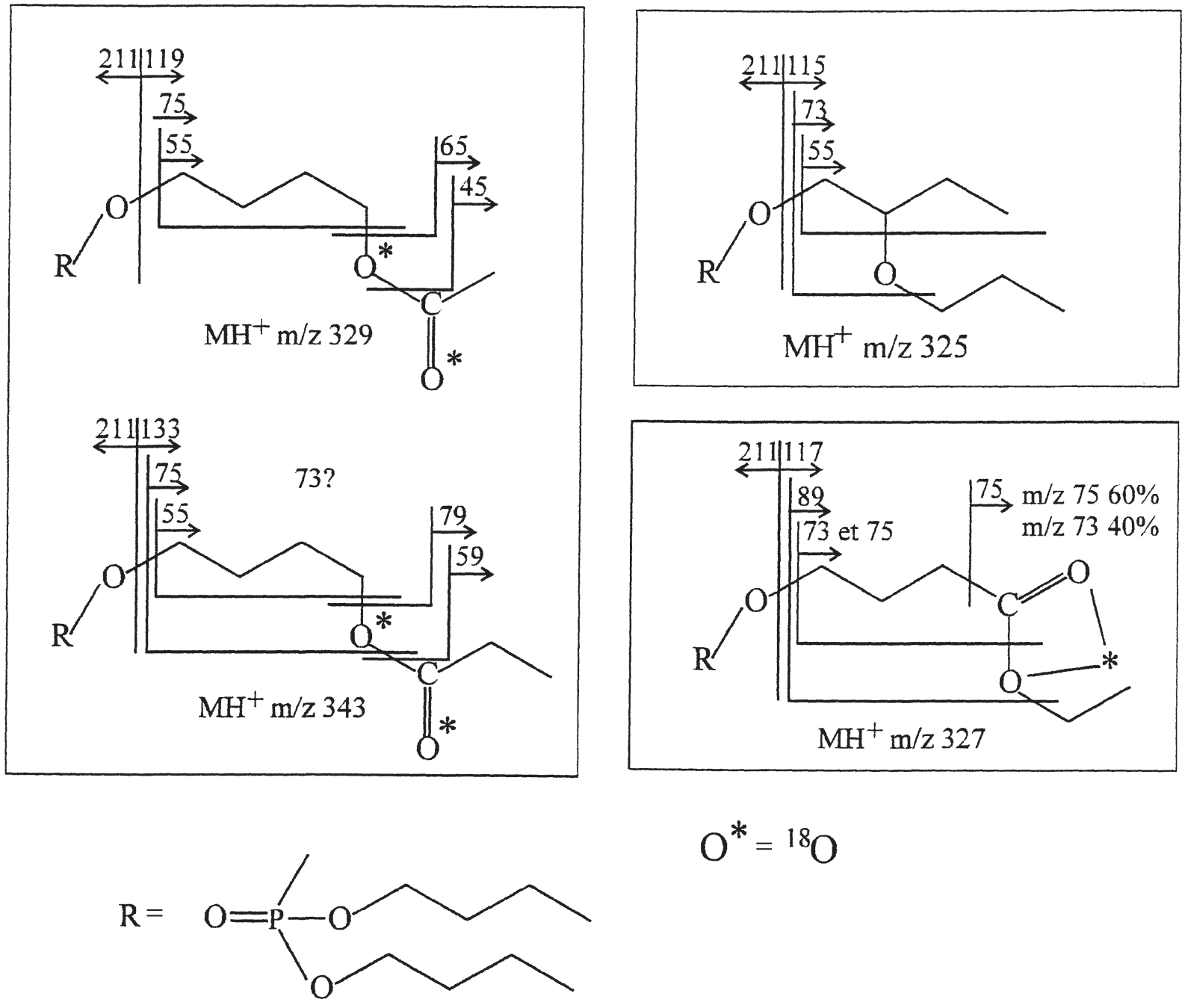

Scheme 7. Comparison of CID fragmentations of labelled and unlabelled oxygenated compounds formed by radiolysis of extraction system (TBP $30 \%$ dodecane/ $\mathrm{HNO}_{3} \mathrm{H}_{2}{ }^{18} \mathrm{O}$ ). $\mathrm{MH}^{+}$ions were prepared under $\mathrm{Cl} / \mathrm{NH}_{3}$ conditions.

impossible to determine the exact position of the oxygen atom on the butyl chains. Nevertheless, radiolysis of carbon-1 hexateuterated TBP $\left(1,1,1^{\prime}, 1^{\prime}, 1^{\prime \prime}, 1^{\prime \prime}-\mathrm{d} 6\right.$ TBP) shows that the oxygen is not on an $\alpha$-carbon.

\subsection{Isotopic labelling results for mechanistic formation studies}

Although the deuterium labelling enabled the identification of all functional group positions on the TBP skeleton, it also allowed to study and establish the formation mechanism of oxygenated TBP derivatives. In particular, the formation of $\mathrm{O}$ - and $\mathrm{C}$-esters $\underline{9 \mathrm{c}}, \underline{9 \mathrm{~d}}$ and 11 during radiolysis of hexadeuterated $1,1,1^{\prime}, 1^{\prime}, 1^{\prime \prime}, 1^{\prime \prime}$-d6-TBP was identified (Scheme 8). The O-esters $\underline{9 c}, \underline{9 d}$ identified are, in all cases, hexadeuterated. The absence of deuterium on the oxygenated carbon chain linked to TBP molecule should be explained by the oxidation of the butyl-1,1-d2 chain in the position 1 or 


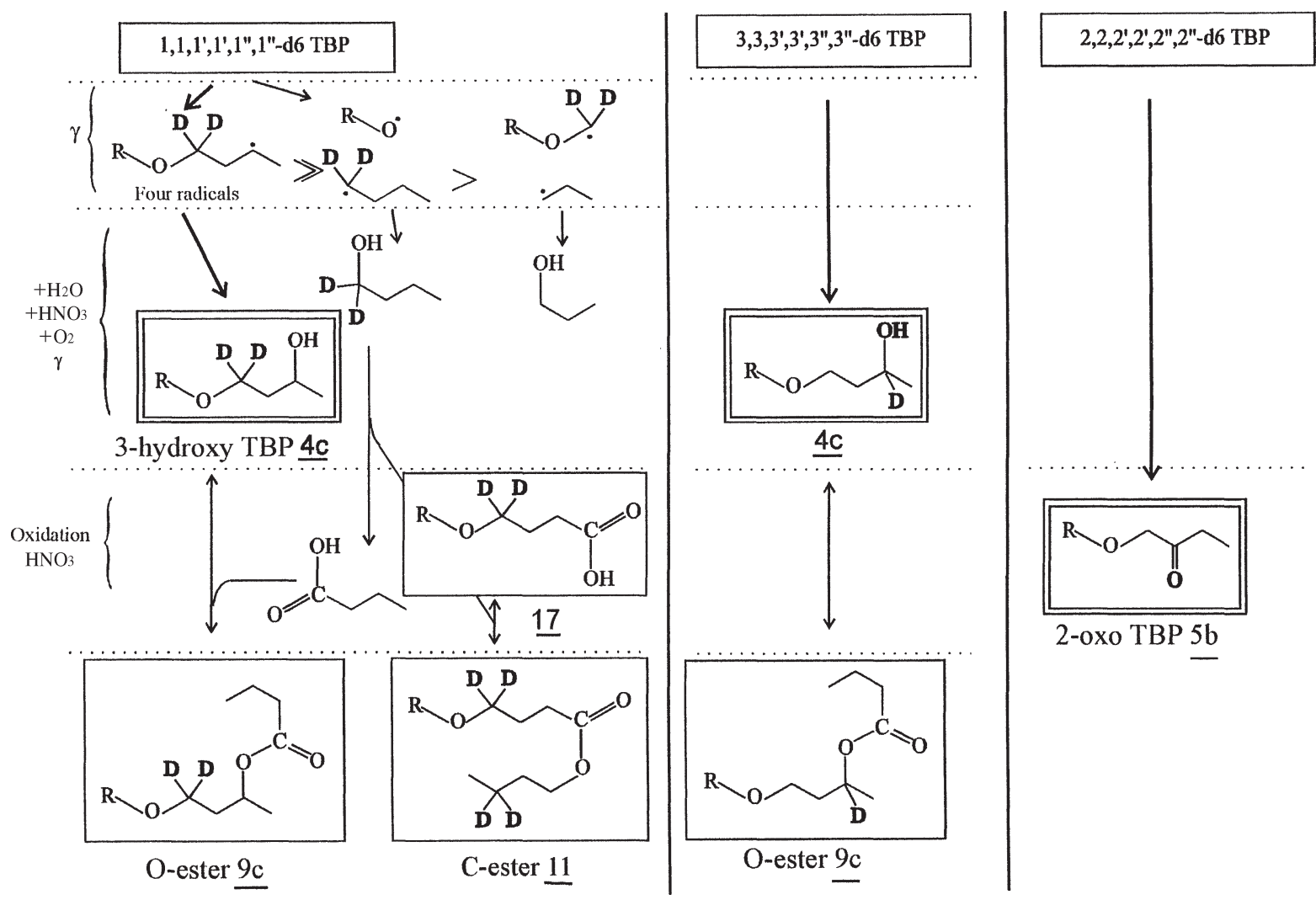

Scheme 8. Deuterated compounds formed during radiolysis of extraction system $\mathrm{TBP}^{*} 30 \%$ dodecane/HNO $\mathrm{HN}_{3} 4 \mathrm{~N}\left(\mathrm{TBP}^{*}\right.$ means $1,1,1,1^{\prime}, 1^{\prime}, 1^{\prime \prime}, 1^{\prime \prime}$-d6 TBP or $2,2,2^{\prime}, 2^{\prime}, 2^{\prime \prime}, 2^{\prime \prime}$-d6 TBP or $3,3,3^{\prime}, 3^{\prime}, 3^{\prime \prime}, 3^{\prime \prime}$-d6 TBP).

via the oxidation of unlabelled propanol, ethanol or methanol chains for the lower homologues TBP derivatives (unshown in Scheme 8).

On the other hand, the C-esters $\underline{11}$ are six or eight times labelled, according to the homologues series studied (e.g., eight times for a butyl chain homologue). As indicated previously, the absence of deuterium loss on the TBP butyl chain reveals the absence of the O-esters $\underline{9 a}$ formation during radiolysis on the 1 substituted TBP.

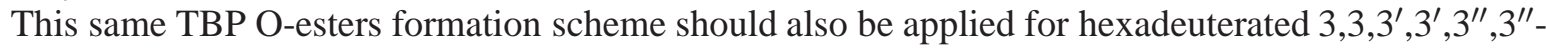
d6 TBP. In this case, however, deuterium loss during the carboxylic acid formation is observed for ethanol or methanol formed from the TBP radicals. This labelling enabled also to differentiate two isomeric O-esters ( $\underline{9 \mathrm{c}}$ or $\underline{9 \mathrm{~d}})$ by the deuterium loss in the first case only. The C-esters $\underline{11}$ are not observed during the radiolysis of hexadeuterated $3,3,3^{\prime}, 3^{\prime}, 3^{\prime \prime}, 3^{\prime \prime}-\mathrm{d} 6$ TBP presumably because this labelled compound was not synthesised with the similar to $1,1,1^{\prime}, 1^{\prime}, 1^{\prime \prime}, 1^{\prime \prime}$-d6 TBP purity. Finally, the deuterium labelling enabled the study of isomeric TBP ethers $\underline{10}$.

The O- and C-esters $(\underline{9 \mathrm{c}}, \underline{9 \mathrm{~d}}$ and $\underline{10})$ were 0,1 or 2 times labelled when $\mathrm{H}_{2} \mathrm{O}$ were substituted by $\mathrm{H}_{2}{ }^{18} \mathrm{O}$ before radiolysis. The total ${ }^{18} \mathrm{O}$ enrichment are $40 \%$ and $27 \%$ for $\mathrm{O}$ - and $\mathrm{C}$-esters, respectively. But the results showed that the ether derivatives of TBP $\underline{10}$ are not labelled. Isotopic abundance patterns for $(M, M+2$ and $M+4)$ corresponded to the expected statistical distribution values assuming the equivalence of 2 oxygen atoms. Similarly, for nitrogen containing derivatives, the nitro compounds $\underline{6}$ were two times labelled (at 35\%) showing the expected isotopic distribution. 


$$
\mathrm{R}^{\prime}=\mathrm{TBP}-\mathrm{H}
$$<smiles>[R]O[N+](=O)[O-]</smiles><smiles>[R][N+](=O)[O-]</smiles>

$\stackrel{\mathrm{O} 2}{\longrightarrow}$ no exchange

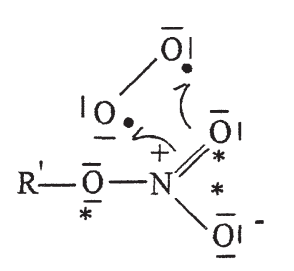

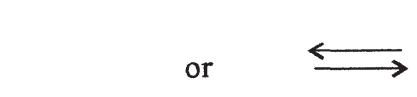

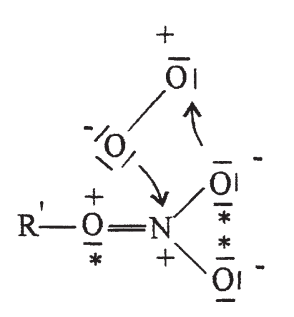

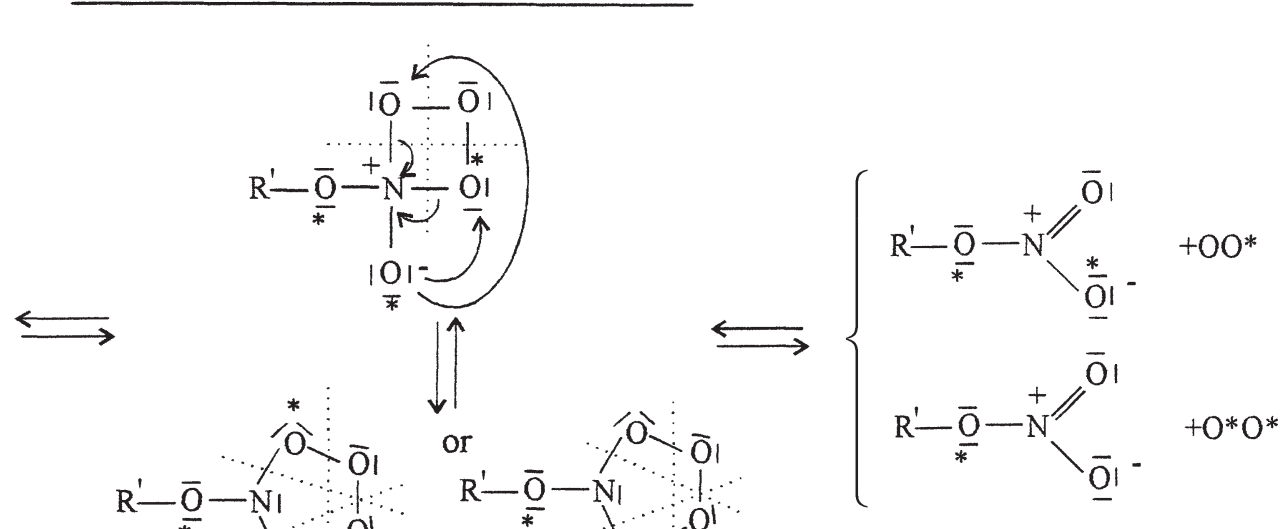

Scheme 9. Exchanges observed labelled for nitroxy TBP $\underline{7}$ and nitro TBP $\underline{6}$.

Nevertheless, nitrate derivatives (7) were one time only labelled (at 65\%), this result suggests the absence of exchange of $\mathrm{C}-\mathrm{O}-\mathrm{N}$ oxygen according to the Scheme 9. Such a weak exchange has been reported in the literature during radiolysis experiments [14].

\subsection{Other remaining components of the mixture}

The radiolysis, as a highly unspecific reaction, should be on the origin of a series of compounds of a general formula of $\mathrm{OP}\left(\mathrm{OC}_{4} \mathrm{H}_{9}\right)_{2}\left(\mathrm{OC}_{y} \mathrm{H}_{2 y+1}\right)$, where $y$ varies from 1 to 3 for inferior and 5 to 18 for superior TBP homologues $\underline{14}$ (Table 1). This last series of derivatives can come from the dodecanes, a major component of hyfrane solvent system. In a similar manner, a series of mono acidic alkyl butyl phosphate as well as unsaturated dibutyl butenyl and dibutyl alkenyl phosphates were identified in a very low concentration (not presented in Table 1). The unsaturated TBP dimers and acidic dibutylphosphate tributylphosphate mixte dimers derivatives and TBP dimer lower homologues $\underline{15}$ were also observed during radiolysis. This series of compounds is discussed in a more detailed manner in our previous paper [4]. 


\section{Conclusion}

The actual state of analysis of solvent degradation enabled to conclude that the minor degradation products remained relatively unknown. It is also clear that some dysfunction of the reprocessing procedure leads to the accumulation of specific trace quantity products. The relatively rich bibliography on this subject [6,7] identified the presence of the families of degradation products rather than the identification of specific isomeric products. The occurrence or absence of some of the expected products justified the formation mechanism study we are presenting in this article.

The major difficulty of nuclear solvent degradation products study remains the complexity of the resulting mixtures. The number of products observed increases with the sensibility of the method applied. The second important difficulty is the limitation of detection techniques used by the constant presence of nitric acid and the radioactivity in this procedure. In order to realise this study we have used the GC-MS-MS technique which is satisfactory on both sensitivity and selectivity levels. The use of stable isotope labellings enabled the identification of some new isomeric or conformation of already known product families as well as precise some coherent general formation mechanism of the TBP derivatives.

The interpretation of isotopic labelling results is based on reliable structure identification (studied via MS-MS) as well as on the formation mechanism. This study enabled to rationalise the most of solvent degradation products formed.

Thus, as discussed in a previous paper [4], the radiolysis of TBP proceeded by the preferential loss of radical $\mathrm{H}^{\circ}$ from $\mathrm{C}-\mathrm{H}$ bond, followed by $\mathrm{O}-\mathrm{C}, \mathrm{C}-\mathrm{C}$ or $\mathrm{O}-\mathrm{P}$ bond cleavages. The radicals formed during radiolysis can interact in several different manner. For instance, their recombination leads to all possible products (except the peroxides). The reaction of carbon radicals under aerobic conditions leads to the hydroxylation of TBP. These alcohols, with nitric acid presence can undergo further oxidation or form-nitrates. This post-radiolytic evolution of mixture presents a double challenge. First, the mixture is in constant evolution, the fragile compounds can be easily transformed into highly oxidated ones. This point makes the quantification of some specific families of compounds in any given mixtures very difficult as well as the reproductivity of analysis. The second point is the difficulty to compare two or more post radiolysis TBP mixtures because of the important interference of work-up conditions (e.g., base or acid treatment) on the results. We have observed an important variation of isomer ratio as well as their evolution accordingly (time, radiation dose). Four isomeric alcohols (hydroxy TBP's) are played a central role in this interaction pattern and their evolution is related to some fine differences in activation (or deactivation) of protons by neighbour phosphate group and controlled by relative stereochemistry of the butyl chain proton phosphate conformation. In particular, the $\alpha$-to hydroxy proton activation by phosphate group is susceptible to accelerate the formation of higher oxidation products.

The MS-MS technique is very useful to study both complex mixtures of products as well as to analyse isotopic labelling assisted results. These techniques enable to identify TBP dimeric structures [4]. These dimers which are sometimes consider negligible and present on the trace quantity level were successfully studied together with products being up to 300 less concentrated. In such a manner the ethers, O- and C-esters together with TBP isomer derivatives were analysed. Most of these products unreported in the literature [6,7], were fully analysed and their structure proposed.

The joint use of MS-MS and isotopic labelling techniques enabled to realise this study directly from the simulating cold sample (without radioactivity). This method is, however, easily transferable, because of the detailed identification of molecular structure of these products, to the radioactive samples 
as well as to follow the evolution of degradation products and in some cases to quantify them. Once the complete identification of degradation products accomplished the use of less expensive and simpler techniques, such as, e.g., $\mathrm{CI} / \mathrm{NH}_{3}$ mass spectrometry, to solve some specific problem is possible and recommended. Finally, it was also possible to obtain the absolute proof of structure identification of solvent system degradation products by their direct comparison to the synthetic model compounds. These synthesis were particularly useful for quantification purposes. The use of reliable synthetic standards was, of course, necessary to validate the quantification study. Next, an equally difficult and complex step is the study of the industrial samples of a real irradiated solvent, which is actually performed in our laboratories. However, the results published in these papers will help in establishing the methodology to realise this objective.

\section{Acknowledgements}

We would like to thank Dr J. Boivin (Ecole Polytechnique, Palaiseau, France), S. Robine (CEA, Saclay) for valuable assistance in synthetic part of this study as well as Dr C. Madic (CEA, Marcoule) and C. Pozo (CEA, Fontenay aux Roses) for helpful comments and for EDIT loop samples preparation.

\section{References}

[1] W.W. Schulz and J.D. Navratil, Science and Technology of Tributylphosphate, CCR Press, FL, 1984.

[2] C. Ginisty and B. Guillame, Separation Sci. Technol. 25 (1990), 1941.

[3] H. Virelizier, Identification de produits lourds formés suite à la dégradation du solvant utilisé pour le retraitement des combustibles irradiés, CEA Research Report SEA no. 062, 1992.

[4] D. Lesage, H. Virelizier, J.C. Tabet and C. Jankowski, Identification of isomeric tributylphosphate dimers formed by radiolysis using tandem mass spectrometry and stable isotopic labelling, European J. Mass Spectrom. (1997), submitted.

[5] C. Pozo, Application de la chromatographie d'exclusion stérique à la séparation de produits de dégradation du solvant de du retraitement des comustibles nucléaires, CEA Research Report CEA-R-5647, 1993.

[6] V.M. Adamov, V.I. Andreev, B.N. Belyaev, G.S. Markov, M.S. Polyakov, A.E. Ritari and A.Yu. Shil'nikov, Kerntechnik 55 (1990), 133.

[7] V.M. Adamov, V.I. Andreev, B.N. Belyaev, G.S. Markov, M.S. Polyakov, A.E. Ritari and A.Yu. Shil'nikov, Radiokhimiya 34 (1992), 189.

[8] E.S. Lane, Nuclear Sci. Eng. 17 (1963), 620.

[9] P. Blanc and M. Deron, Technical Report DPR/SEMP/SECP 91/21 Aout 91, CEA, France.

[10] C. Ginisty and P. Blanc, Technical Report DPR/SEMP/SECP 91/22 Aout 91, CEA, France.

[11] M.C. Charbonnel and P. Blanc, Technical Report DPR/SEMP/SECP 91/23 Aout 91, CEA, France.

[12] E.S. Finne, J.S. Gunn and T.S. Sorensen, J. Amer. Chem. Soc. 109 (1987), 7816.

[13] D. Raederstorff, A.Y.L. Shu, J.E. Thompson and C. Djerassi, J. Org. Chem. 52 (1987), 2344.

[14] E.W. Holtzscheiter, The study of the radiation induced exchange of oxygen-18 in inorganic molecular ions, Thesis, 1973.

For some mass references of TBP and phosphates see, e.g.,

[15] P.A. Cload and D.W. Hutchinson, Org. Mass Spectrom. 18 (1983), 57.

[16] P.A. D’Agostino and L.R. Provost, Biomed. Environ. Mass Spectrom. 13 (1994), 231.

[17] P.A. D’Agostino and L.R. Provost, J. Chromatogr. A670 (1994), 127.

[18] C.S. Harden, A.P. Snyder and G.A. Eiceman, Org. Mass Spectrom. 28 (1993), 585.

[19] G.S. Groenewold, J.C. Ingram, J.E. Delmore and A.D. Appelhans, J. Amer. Soc. Mass Spectrom. 6 (1994), 165.

[20] K.M. Stirk, P. Lin, T.D. Ranatunga, L.C. Zeller, J.T. Farrel and H.I. Kenttämaa, Int. J. Mass Spectrom. Ion Processes 130 (1994), 187. 


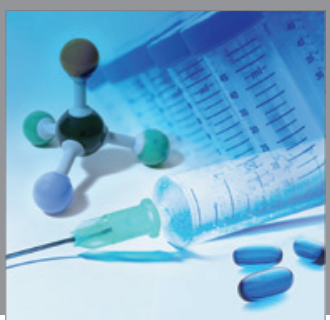

International Journal of

Medicinal Chemistry

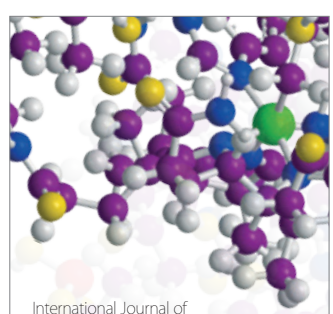

Carbohydrate Chemistry

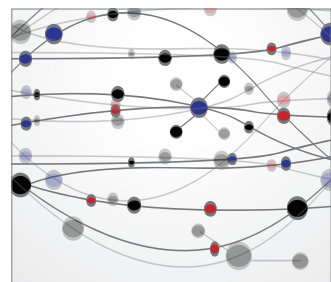

The Scientific World Journal
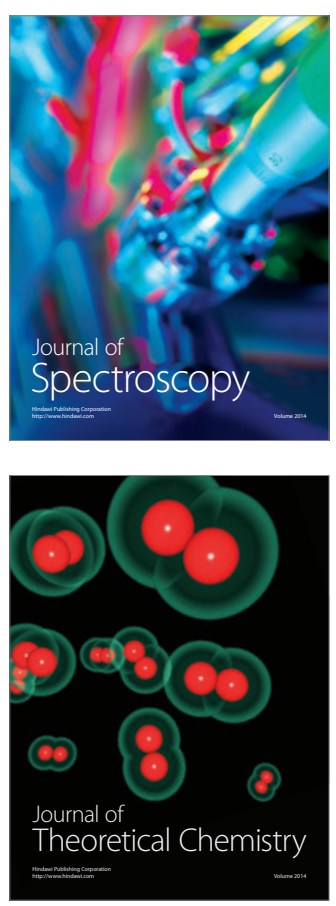
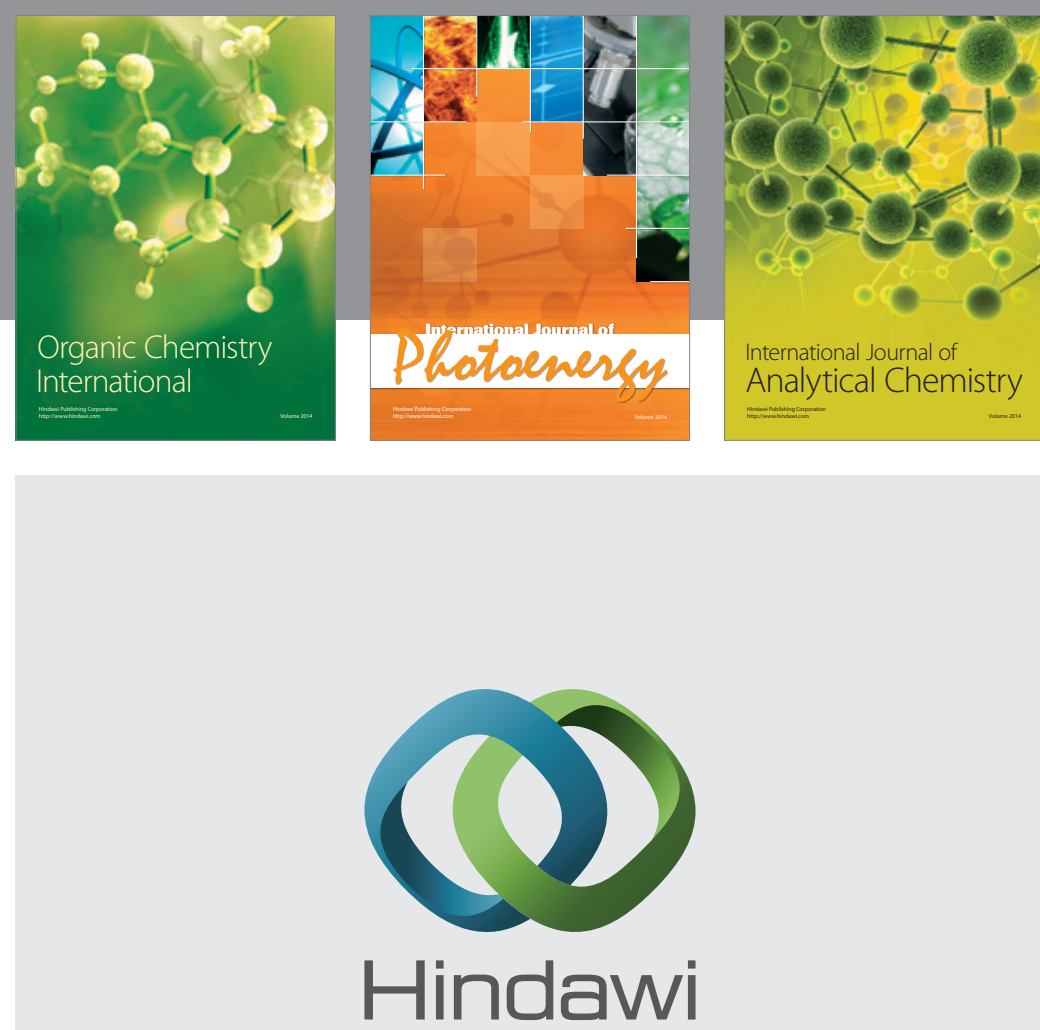

Submit your manuscripts at

http://www.hindawi.com
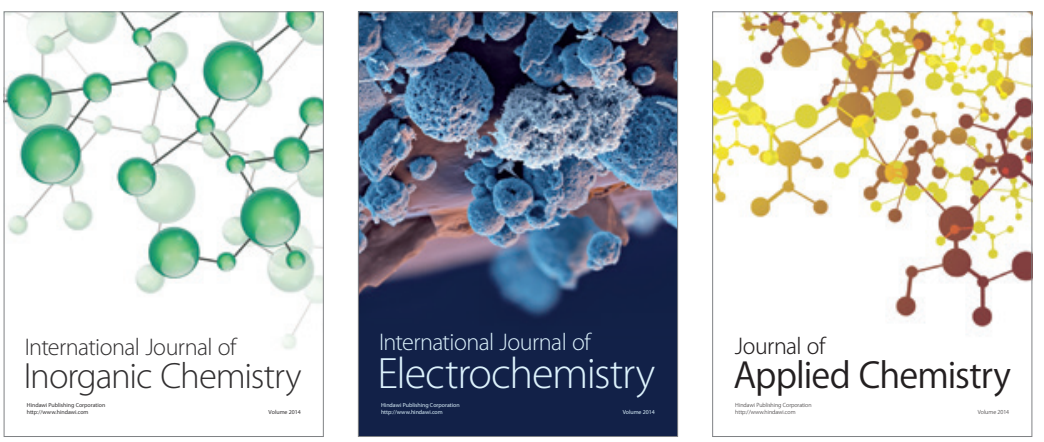

Journal of

Applied Chemistry
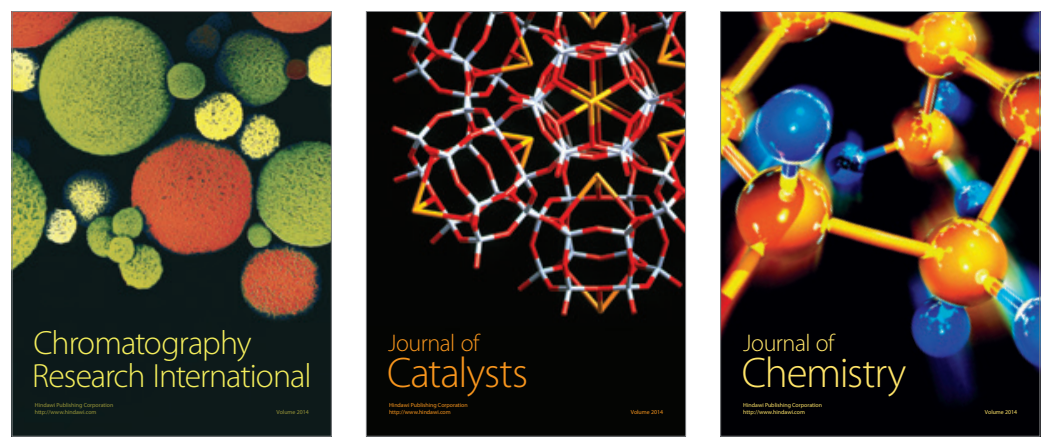
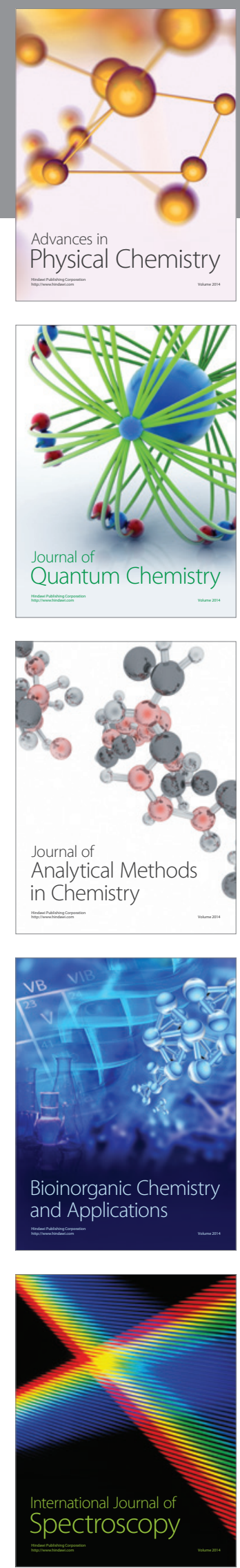